The Korean Journal of Parasitology

Vol. 37, No. 4, 277-283, December 1999

\title{
Expression of major piroplasm protein (p33) of Theileria sergenti (Korean isolate) and its immunogenicity in guinea pigs
}

\author{
Seung-Won KANG*, Chang-Hee KWEON, Eun-Jin CHOI and Yong-Dhuk YOON
}

National Veterinary Research and Quarantine Service, MAF,

Anyang, 340-016, Korea

\begin{abstract}
To investigate the development of a subunit vaccine against theileriosis in cattle, the DNA fragments encoding piroplasm surface protein (p33) of Theileria sergenti of a Korean isolate were expressed in baculoviruses. The expressed p33 was characterized by indirect fluorescent antibody (IFA) and western blotting analysis. The expression of p33 was mainly detected on the surface of infected Sf2 1 cells by IFA. The immunoblotting analysis revealed the presence of a same molecular weight protein band of $\mathrm{p} 33$. The antigenicity of expressed polypeptide was further examined through the inoculation of a guinea pig. The sera of guinea pigs immunized with p33 expressed cell lysate showed similar fluorescent antibody patterns and reacted with the same molecular weight protein of $T$. sergenti in immunoblotting analysis, thus indicating that this protein can be a promising candidate for a subunit vaccine in the future.
\end{abstract}

Key words: Theileria sergenti, subunit vaccine, expression, piroplasm surface protein (p33), merozoite, baculovirus, piroplasm

\section{INTRODUCTION}

Theileria sergenti is the causative agent of theileriosis in cattle and goats. Clinically, theileriosis causes fever and chronic anemia, thus leading to great economic losses in affected countries (Radley et al., 1975; Soulsby et al., 1982).

Theileriosis, through persistant infections in dairy cattle since the 1970 s, is considered to be one of the most important diseases in cattle. In spite of the long period of effort from both farmers and the government, cattle are continuously being infected with $T$. sergenti in

- Received 6 August 1998, accepted after revision 4 November 1999.

*Corresponding author (e-mail: kangsw@ mail.nvrqs.go.kr)
Korea (Chang, 1974; Kim and Son, 1983, 1984).

The control of theileriosis relies on the application of acaricides to reduce tick infestation on animals that exhibit a degree of resistance to the disease. Although live attenuated vaccines or blood vaccines have been experimentally produced for theileriosis, their applications have been limited due to relatively large amounts of antigen are required to properly assess the value of candidate vaccine antigens in vitro (Brown et al., 1971; Burridge et al., 1972; Cunningham et al., 1974; Baek et al., 1991).

However, DNA technology offers a valuable alternative. The manipulation of the gene enables the antigen of interest to be producd in large amounts using expression systems.

Recently, study on subunit vaccines has focused on identifying antigens and their 
immune responses that are likely to mediate protection. Among subunit vaccine candidates, a piroplasm surface protein of $33 \mathrm{kDa}$ (p33) is reported to be an immunodominant antigen expressed on the surface of piroplasms of $T$. sergenti (Kawazu et al., 1992a, 1992b, 1997). Previously, we characterized the gene encoding p33 of $T$. sergenti isolated in Korea (Kang et al., 1997).

In this study, we expressed p33 of $T$. sergenti using a recombinant baculovirus, because this expression system is known not only to produce high amounts of recombinant proteins, but it is easy to analyze the posttranslational modifications including glycosylation in eukaryotes (Matsura et al., 1987). We also report the immunogenecity of recombinant p33 in laboratory animals as a possible candidate for subunit vaccine.

\section{MATERIALS AND METHODS}

\section{Construction of recombinant baculo- virus expressing p33 of $T$. sergenti}

The cloning and amino acid sequences of the gene encoding p33 of $T$. sergenti of a Korean isolate has been previously described (Kang et al., 1997). For construction of the transfer vector for baculovirus expression, the cloned p33 in pUC19 plasmid was digested with BamHI (Promega) and EcoRI (Promega, Madison, USA). The digested DNA of p33 was then extracted after gel electrophoresis. The extracted DNA fragments were ligated with Aurographa california nuclear polyhedrosis virus (AcNPV) transfer vector. For site directed ligation, BacPAK8 (Clonteck, Palo Alto, USA) vector was also digested with BamHI and EcoRI within cloning sites before ligation with p33 gene as shown in Fig. 1. Through sitedirected ligation, the ATG starting codon of p33 was directly located behind the AcNPV promoter with its own initiation and terminating codon within the transfer vector. The ligated transfer vector was then cotransfected into Spodoptera frugiperda (Sf21) cells (Invitrogen, Carlsbad, USA) with wild-type baculovirus DNA using Lipofectin (GibcoBRL, Gaithersburg, USA). The recombinant baculoviruses were plaque purified twice by the procedures as described previously (Kweon et al., 1997a, 1997b). Plaque purified recombinant baculoviruses were concentrated and subjected to PCR for the identification of an inserted p33 DNA in baculoviruses as described before (Choi et al., 1997; Kweon et al., 1997b). The positive clones were further propagated in Sf2 1 cells and screened through the indirect immunofluorecent antibody (IFA) assay using positive bovine sera against $T$. sergenti.

\section{Characterization of p33 expressed in recombinant baculovirus}

For the identification of expressed p33, Sf2 1 cells were infected with the recombinant baculovirus at a multiplicity of 0.1-1 per cell. The infected cells were then incubated at $28^{\circ} \mathrm{C}$ for 48-72 $\mathrm{hr}$ and examined by indirect IFA method. The cells were fixed with cold acetone for $10 \mathrm{~min}$ and reacted with a 1:50 dilution of positive bovine sera against $T$. sergenti for $1 \mathrm{hr}$ at $37^{\circ} \mathrm{C}$ followed by washing with PBS. FITC conjugted anti-bovine immunoglobulin (KPL, Gaithersburg, USA) was reacted at the same conditions before examination for fluorescence. The infected cell lysates were also subjected to SDS-PAGE and immunoblotting for the detection of expressed proteins.

\section{Immunogenicity of expressed proteins}

To detect immunogenicity of expressed proteins in vivo, the recombinant baculovirus infected Sf2 1 cells were scraped at $72 \mathrm{hr}$ postinfection. The infected cell lysates were prepared as described previously (Kweon et al., 1997b). Four-week-old guinea pigs were injected using freeze-thawed cell lysates mixed with equal volume of Freund's complete adjuvant (Sigma, St. Louis, USA). The second injection with Freund's incomplete adjuvant (Sigma) followed after three weeks, and the last injections were conducted without any adjuvant. After two weeks, the blood was collected and tested for IFA and immunoblotting. IFA was conducted using the same procedures mentioned above using $T$. sergenti-infected blood from cattle. SDS-PAGE and immunoblotting were carried out using the procedure of Laemmli (1970) and Towbin et al. (1979), respectively. The subsequent immunodetection procedures were conducted 
with serum of guinea pigs immunized with p33 expressed Sf2 1 cell lyates as described previoulsy (Kweon et al., 1997b).

\section{RESULTS}

\section{Cloning and construction of recombi- nant baculovirus}

The transfer vector for p33 (860 bp) was constructed with the pBacPAK8 vector using BamHI and EcoRI restriction sites, which contain an ATG initiation codon of p33 of $T$. sergenti right behind AcNPV polyhedron promoter (Fig. 1).

In a transfection experiment, two recombinant baculoviruses were cloned from inoculation of $10^{-5}$ and $10^{-6}$ dilutions of transfected Sf2 1 cell-supernatant through plaque assay. When the inserted p33 DNA from recombinant baculoviruses was tested by PCR, the same size of p33 DNA was amplified (Fig. 2), thus confirming that two recombinant baculoviruses contained the gene for p33 of $T$. sergenti.

\section{A}

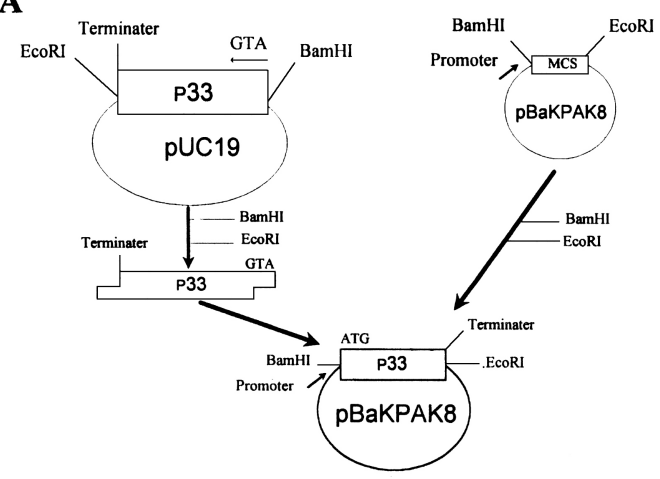

B

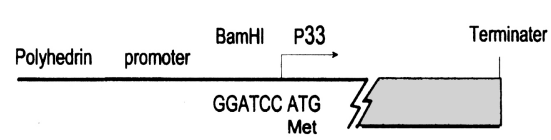

Fig. 1. Construction of transfer vector for baculovirus expression. A. DNA fragment containing p33 of $T$. sergenti was ligated with a transfer vector (pBaKPak8) using BamHI and EcoRI site. B. Nucleotide sequences of recombinant transfer vector in pBaKPAK8. First translational codon (ATG) of p33 is indicated with an arrow.

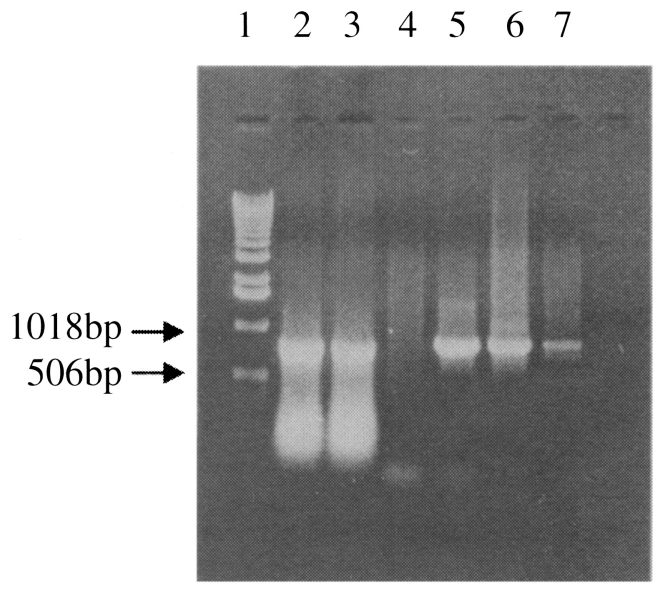

Fig. 2. Identification of a p33 gene of $T$. sergenti from recombinant AcNPV by PCR. Lane 1 , Standard size marker; lane 2, recombinant AcNPV clone 1; lane 3, recombinant AcNPV clone 2; lane 4, control AcNPV; lane 5 and 6, positive standard PCR; lane 7, positive isolate (Sunghwan), respectively.

\section{Characterization of expressed p33 of $T$. sergenti}

Initially, the detection on expression of p33 was screened in recombinant virus infected Sf2 1 cells by IFA. Positive results were only detected in cells infected with recombinant virus. The immunofluorescence was mainly observed on the cytoplasm and the surface of virus infected cells (Fig. 3). Since the immunofluorescence was observed after the initiation of cytopathic effects in Sf21 cells, positive clones were further selected for the identification of expressed protein by immunolotting.

When the cell lysate was subjected to SDSPAGE, one extra protein band of $33 \mathrm{kDa}$ was clearly detected in virus infected cells, but not in the control (Fig. 4).

\section{Immunogenicity of p33 in laboratory animals}

In order to investigate the immunogenicity of expressed p33 protein, guinea pigs were immunized with cell lysates. The sera from immunized guinea pigs were then tested by IFA and immunoblotting. When the sera from guinea pigs were examined by IFA, positive reactions were observed up to 32-64 dilution 

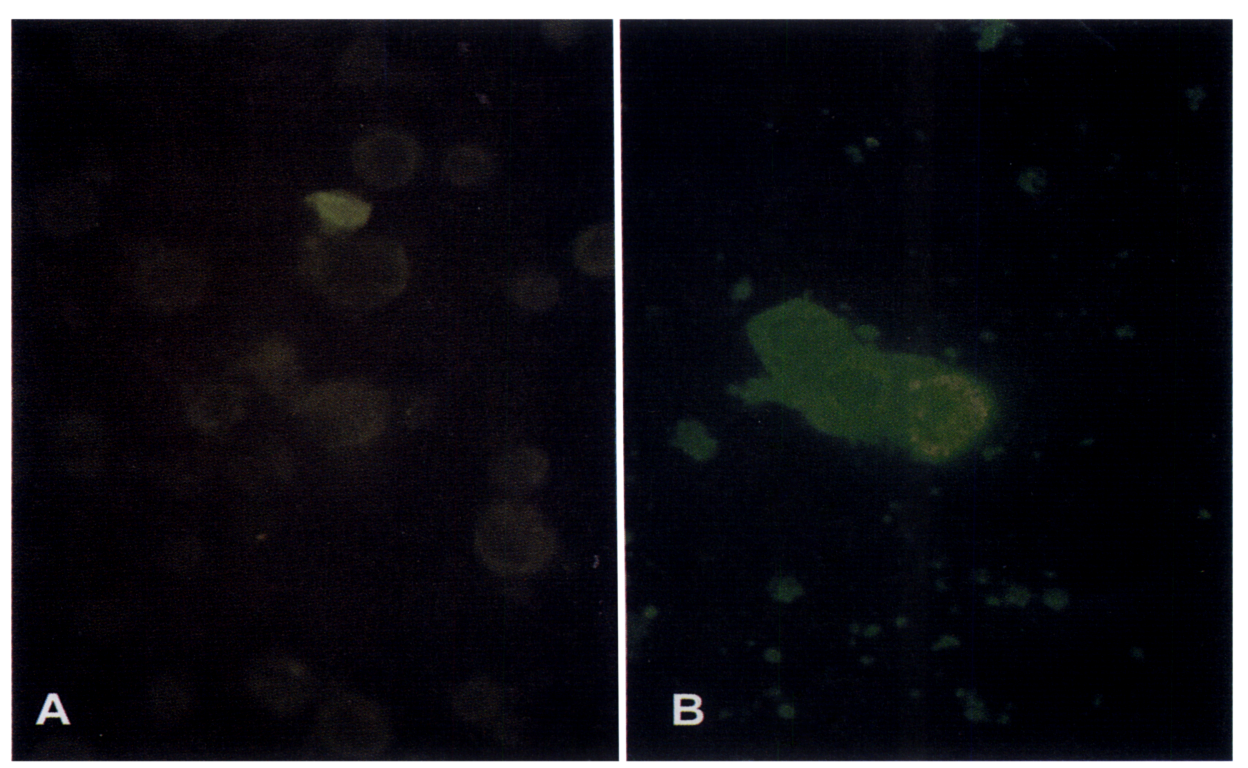

Fig. 3. Immunofluorescence of Sf 21 cells. A. Control cells. B. cells infected with recombinant baculovirus cloned from $10^{-6}$ dilution of transfection supernatant. Cells were reacted with $T$. sergenti positive bovine serum (1:50. X660.

(Fig. 5). In immunoblotting, although several protein bands were detected, the $33 \mathrm{kDa}$ protein band was also detected with immunized sera (Fig. 6). The detection on several protein bands was rather expected because the immunizing cell lysate was prepared from virus infected cells and resulted in cross-reaction with other proteins of similar immunogenicity. However, sera from immunized guinea pigs also revealed positive titers $(1: 32$ or $1: 64)$ similar to those of bovine sera collected from cattles infected with $T$. sergenti (data not shown).

\section{DISCUSSION}

Previous studies indicate that the major surface protein of $T$. sergenti could induce immunoprophylatic effects in cattle (Baek et al., 1990, 1992). We constructed recombinant baculoviruses expressing p33 of $T$. sergenti as a potential candidate for a subunit vaccine. In this study, it was shown that $\mathrm{p} 33$ was detected on the surface of infected Sf2 1 cells by IFA, which correlates favorably with the finding that p33 is expressed on the surface of parasites during the erythrocyte stage as an integral membrane protein (Shirakara et al.,
1989). A predicted amino acid sequence for p33 shows a hydrophobic membrane-anchor stretch at the C-terminal end and a signal peptide sequence at the $\mathrm{N}$-terminus (Kawazu et al., 1992a; Matsuba et al., 1993). Thus, the recombinant p33 is thought to be transported to the cell surface after glycosylation and then anchored into the membrane of Sf2 1 cells.

In addition, we also demonstrated that p33 from recombinant baculovirus had a molecular size similar to that of the original protein of $T$. sergenti. Although the exact properties of glycosylation and comparison of expressed p33 in this study requires further characterization, immunoblotting and IFA results supported our expectation that p33 from baculovirus had properties similar to those of p33 of $T$. sergenti. In these respects, baculovirus expression for the parasite molecule using insect cells can be used as a model of secondary modification by the parasites growing in host erythrocytes and can be useful for antigenic analysis of p33 variants (Matsura et al., 1987; Maeda, 1989).

In this study, we used the p33 expressed cell lysate instead of purified p33 because the purification steps of the recombinant proteins or the purified proteins themselves often might 


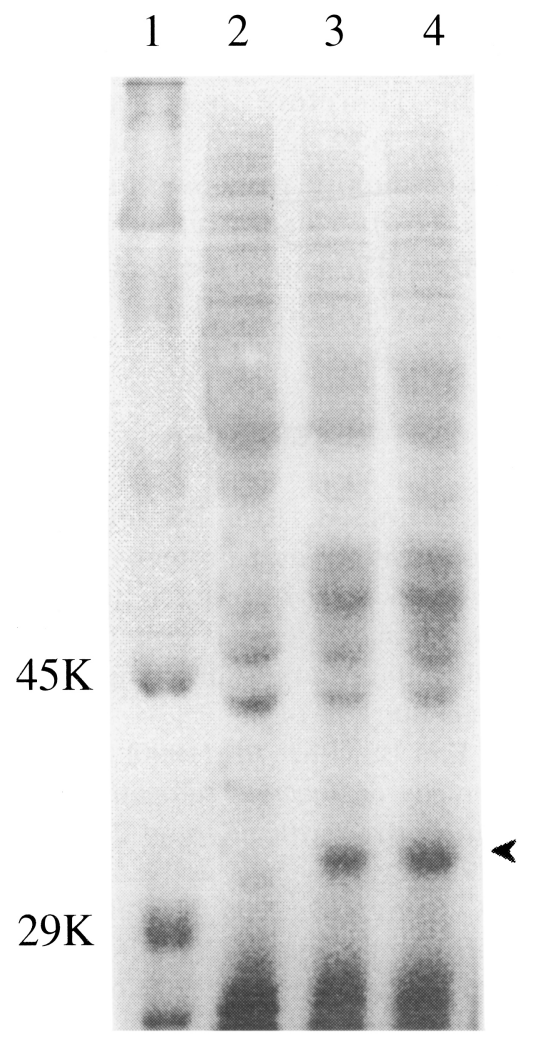

Fig. 4. Identification of p33 protein expressed in Sf2 1 cells infected with recombinant AcNPV by SDS-PAGE (12\%). Lane 1, standard size marker; lane 2, Control-Sf 21 cell-lysates; lane 3 and 4 , Sf2 1 cell-lysates infected with recombinant AcNPV cloned from the dilution of $10^{-5}$ (lane 3 ) and $10^{-6}$ (land 4) from transfected supernatant, respectively.

lose the initial immunity or biological function (Martinez-Torrecurada et al., 1996).

It has been reported that due to the genetic and antigenic diversities of parasites, some part of the parasite population can become dominant during the course of infection, which results in obvious phenotypic or genotypic alteration of the parasites (Matsuba et al., 1993). The humoral immunity may be one of the host factors which selects the dominant population in the mammalian host.

There are some reports about the immunodominant proteins in $T$. sergenti which can infect cattle in Korea, Japan, Russia, and Australia, even though there are no reports on the presence of $T$. buffeli in Korea (Kawazu et al., 1992b; Kubota et al., 1996). The p32 has

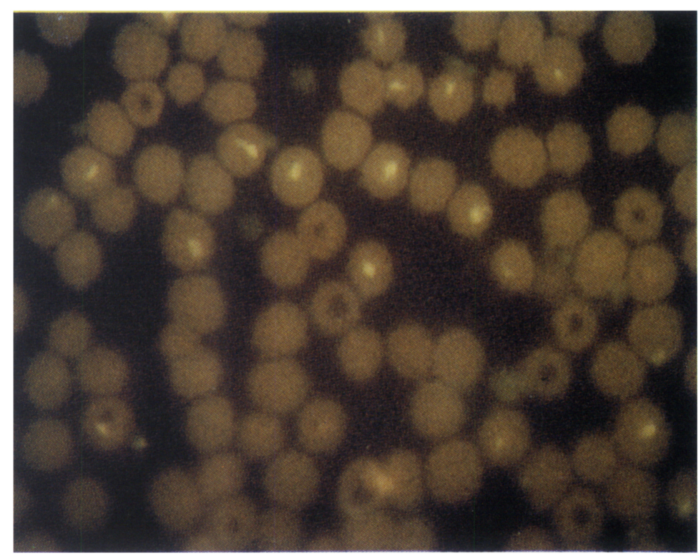

Fig. 5. Indirect fluorescence antibody test of $T$. sergenti-infected RBC with guinea pig serum immunized with Sf21 cell-lysate infected by recombinant baculovirus. $\mathrm{X} 1,200$.

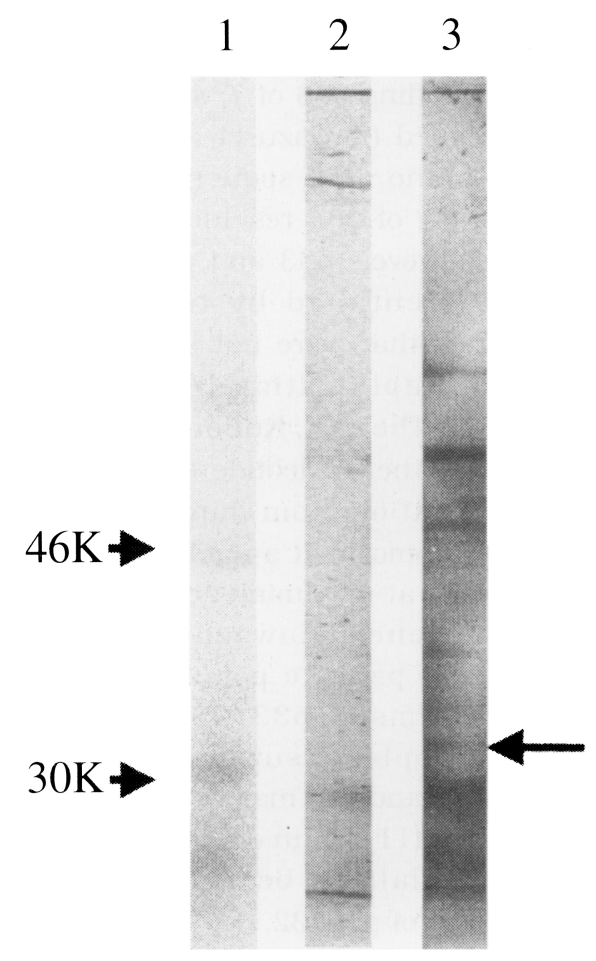

Fig. 6. Immunoblotting analysis of $T$. sergenti with sera of guinea pig immunized with recombinant baculovirus infected Sf21 celllysates. Lane 1, Standard M.W.marker; lane 2, T. sergenti reacted with guinea pig serum raised from wild AcNPV infected Sf21 cell lysates; lane 3 , T. sergenti reacted with guinea pig serum raised from p33 expressing recombinant AcNPV infected Sf2 1 cell lysates. 
been isolated and analyzed (Shirakata et al., 1989; Matsuba et al, 1993) and the recombinant baculovirus p32 antigen and synthetic peptide p32 were produced and used to vaccinate calves (Matsuba et al., 1995; Onuma et al., 1997). Mixed population in T. sergenti stocks and isolates were analyzed genetically by allele-specific polymerase chain reaction (Kawazu et al., 1992b). In this experiment, it was suggested that the majority of $T$. sergentiinfected calves in Japan harbor a mixed parasite population bearing at least two different alleles of p33/32. However, there is $77 \%$ of identity by comparing the gene sequences of the mRNA for p32 to the mRNA for p33 (GenBank, NCBI, USA).

The $33 \mathrm{kDa}$ ( $T$. sergenti merozoite) and 34 $\mathrm{kDa}(T$. buffeli merozoite) proteins are exposed on the piroplasm surface, suggesting that they are the most immunodominant proteins in infected cattle. The nucleotides sequences of the cDNA encoding p33 of $T$. sergenti and p34 were determined (Kawazu et al., 1992b). The predicted amino acid sequence of p33 and p34, consisting of 283 residues, showed $82 \%$ similarity. However, p33 and p34 genes were clearly differentiated by the restriction enzymes sites that were not shared between them after amplification (Kawazu et al., 1992b). Nevertheless, Kubota et al. (1996) indicated that the nucleotide sequence of the gene amplification from Japanese isolates showed 89\% homolgy at a nucleotide level and $88 \%$ homology at an amino-acid level with $T$. buffeli p34 genes. Kawazu et al. (1995) suggested that parasite populations bearing two allelic forms of p33/32 (an immunodominant piroplasm surface protein of $T$. sergenti) exist, and the majority of $T$. sergentiinfected calves $(11 / 15)$ in Japan harbor mixed parasite populations bearing at least two different alleles of p33/32.

Kubota et al. (1996) reported that a dominant parasite population was demonstrated during transmission from calves to vector ticks and from infected ticks to calves. Parasite population changes were also apparent during persistent infection in cattle over several months. This change is thought to occur under host immune pressure, and it indicates that expression of diverse forms of $\mathrm{p} 33 / 32$ may play a role in parasite persistence within mammalian hosts and its transmission from tick vector. Therefore, it is reasonable to expect that p32 and p33 proteins are important to immune responses in the cattle.

In this study, we provided the initial characterization of expressed protein (p33) for developing a cocktailed subunit of immunodominant epitopes in the future.

\section{REFERENCES}

Baek BK, Choi IH, Kim BS, et al. (1992) Immunogenicity and protective efficacy of solubilized merozoite-enriched Theileria sergenti immunogens. I: Protection against homologous stabilate challenge. Korean $J$ Parasitol 30: 133-140.

Baek BK, Kim BS, Rhee JK (1990) Study on the antigenicity of Theileria sergenti merozoite in Korean native cattle. Korean $J$ Vet Res 30: 223-229.

Baek BK, Song HJ, Kim BS, et al. (1991) Immunoprophylactic studies of of hemotropic parasites in cattle. V. Blood clinicopathological observation and changing of body weight according to vaccination. Korean $J$ Vet Publ Hlth 15: 127-141.

Brown CGD, Malmquist WA, Cunningham MP, et al. (1971) Immunization against East Coast Fever. Inoculation of cattle with Theileria parva schizonts grown in cell culture. $J$ Parasitol 57: 59-60.

Burridge MJ, Morzaria SP, Cunningham MP, et al. (1972) Duration of immunity to East coast fever (Theileria parva infection of cattle). Parasitology 64: 511-515.

Chang DH (1974) Epidemiological study of theileriosis (East coast fever). Korean $J$ Parasitol 12: 14-20.

Choi EJ, Kang SW, Kweon CH, et al. (1997) Rapid detection of Theileria sergenti by polymerase chain reaction. Korean $J$ Parasitol 35: 111117.

Cunningham MP, Brown CGD, Burridge MJ (1974) Theileriosis: The exposure of immunized cattle in a Theileria lawrencei enzootic area. Trop Anim Hlth Prod 6: 39-43.

Kang SW, Choi EJ, Kweon CH (1997) Cloning and sequencing of p33 in a Korean isolate of Theileria sergenti. Korean J Parasitol 35: 105110.

Kawazu S, Kamio T, Sekizaki T, et al. (1995) 
Theileria sergenti and T. buffeli: polmerase chain reaction-based marker system for differentiating the parasite species from infected cattle blood and infected tick salivary gland. Exp Parasitol 81: 430-435.

Kawazu S, Okumura T, Hirogari Y, et al. (1997) A polymorphism observed in the experimentally successful peptide vaccine sequence derived from Theileria sergenti piroplasm major surface antigen (p33). $J$ Vet Med Sci 59: 829831.

Kawazu S, Sugimoto C, Kamio T, et al. (1992a) Analysis of the genes encoding immunodominant piroplasm surface proteins of Theileria sergenti and Theileria buffeli by nucleotide sequencing and polymerase chain reaction. Mol Biochem Parasitol 56: 169-175.

Kawazu S, Sugimoto C, Kamio T, et al. (1992b) Antigenic differences between Japanese Theileria sergenti and other benign Theileria species of cattle from Australia (T. buffeli) and Britain (T. orientalis). Parasitol Res 78: 130135.

Kim IC, Son JY (1983) Studies on the change of blood values and daily milk yield after parturition on holstein cows infected with Teileria sergenti in the farm where tick population is sparse. Korean $J$ Anim Sci 25: 464-459.

Kim IC, Son JY (1984) Studies on the change of blood values and daily milk yield after parturition on holstein cows infected with Teileria sergenti in the farm where tick population is dense. Korean J Anim Sci 26: 137-144.

Kubota S, Sugimoto C, Onuma M (1996) Population dynamics of Theileria sergenti in persistently infected cattle and vector ticks analysed by a polymerase chain reaction. Parasitology 112: 437-442.

Kweon CH, Kang SW, Choi EJ, et al. (1999) Bovine herpes virus expressing envelope protein (E2) of bovine viral diarrheal virus as a vaccine candidate. $J$ Vet Med Sci, 61: 395401.

Kweon CH, Lee JG, Han MG, et al. (1997a) Rapid diagnosis of porcine epidemic diarrhea virus infection by polymerase chain reaction. $J$ Vet Med Sci 59: 231-232.
Kweon CH, Yoon YD, An SH, et al. (1997b) Expression of envelope protein (E2) of bovine viral diarrhea virus in insect cells. $J$ Vet Med Sci 59: 415-419.

Laemmli UK (1970) Cleavage of structural proteins during the assembly of the head of bacteriophage T4. Nature 227: 680-685.

Maeda S (1989) Expression of foreign genes in insects using baculovirus vectors. Ann Rev Entomol 34: 351-372.

Martinez-Torrecuada JL, Diaz-Laviada M, Roy P, et al. (1996) Full protection against African horsesickness(AHS) in horses induced by baculovirus-derived AHS virus serotype VP2, VP5 and VP7. J Gener Virol 77: 1211-1221.

Matsuba T, Kubota H, Tanaka M, et al. (1993) Analysis of mixed parasite populations of Theileria sergenti using cDNA probes encoding a major piroplasm surface protein. Parasitology 107: 369-377.

Matsuba T, Sugimoto C, Hattori M, et al. (1995) Expression of a $32 \mathrm{kD}$ Theileria sergenti piroplasm surface protein by recombinant baculoviruses. Int $J$ Parasitol 25: 939-943.

Matsura Y, Posses RD, Overton HA, et al. (1987) Baculovirus expression vectors: the requirement for high level expression of proteins, including glycoproteins. $J$ General Virol 68: 1233-1250.

Onuma M, Kubota S, Kakuda T, et al. (1997) Control of Theileria sergenti infection by vaccination. Trop Anim Hlth Prod 29: 119S$123 \mathrm{~S}$.

Radley DE, Brown CGD, Cunningham MP, et al. (1975) Challenge of immunized cattle by prolonged exposure to infected ticks. Vet Rec 14: 525-527.

Shirakata S, Onuma M, Kirisawa R, et al. (1989) Localization of surface antigens on Theileria sergenti merozoite by monoclonal antibodies. Jpn J Vet Sci 51: 831-833.

Soulsby EJL (1982) Helminths, arthropods and protozoa of domesticated animals, 7 th ed. pp507-665, Bailliere Tindal, London, UK.

Towbin H, Staehelin T, Gordon J (1979) Electrophoretic transfer of proteins from polyacrylamide gels to nitrocellulose sheets. Proc Natl Acad Sci USA 76: 4350-4354. 